\title{
Arthroscopic Fixation Of Tibial Spine Avulsion Fractures: Strangulation Technique
}

\author{
Neel M Bhavsar, Rameez A Musa, Sunil S Chodavadiya*, Trunal J Patel and Pankaj R Patel \\ Department of Orthopaedics, NHL Municipal Medical College, India \\ *Corresponding author: Dr Sunil S Chodavadiya, Department of Orthopaedics, NHL Municipal Medical College, India
}

\begin{abstract}
Introduction: Tibial spine avulsion fracture is rare injury. Various methods have been described to treat these injuries. We are demonstrating the results of arthroscopic fixation of these fractures using strangulation technique.

Materials and Methods: 10 Patients with displaced tibial spine avulsion fractures without other associated ligament injuries were included in the study. Patients underwent arthroscopic fixation using strangulation technique. The postoperative results were analyzed using clinical tests, radiological evaluation and Lysholm score.

Observations and Results: We evaluated all 10 patients at final follow up. Radiographs showed that all fracture healed anatomically and all patients reported no symptoms of instability, such as giving - way episodes, clinical signs of anterior cruciate ligament deficiency were negative. Functional outcome assessed with help of Lhysolm score on each follow up. One patient had restricted range of motion in post op period.

Conclusion: Arthroscopic fixation of tibial spine avulsion fractures using strangulation technique is reliable technique, which gives excellent functional outcomes.
\end{abstract}

Keywords: Arthroscopy; Pull through suture; Tibial spine avulsion; Strangulation technique; Fiber tape

\section{Introduction}

Tibial spine fractures are relatively rare with an approximated incidence of 3 per 100,000 per year.1The age group which is more commonly involved in these fractures is 8-14 years of children.2Because during these years of age strength of the ligaments is more than the ossifying tibial eminence bone. Though recently there has been increase in the incidence of these fractures in adults 3 . Hayes et al found that $40 \%$ of tibial eminence fractures reported in the literature occurred in adults4.

As tibial spine is the attachment site of ACL, insufficiency of the ACL is associated with tibial spine avulsion fractures.5 In adults' mode of injuries are usually high energy trauma like RTA, Sports etc, so concomitant injuries to collateral ligaments and menisci occurs more in adult age group5. The Meyers and Makeover classification6, is the most commonly used classification of tibial spine fractures. This injury produces disabilities in form of flexion deformity, loss of extension and instability of the knee joint as ACL is also involved, so it is important to fix this injury (especially type 3 and 4).09,10,11It is also important to fix this injury with prevention of native ACL because it has mechanoreceptors for proprioception and neuromuscular control.12Various methods have been described to fix this fracture which includes k-wire13, cancellous screws14, Herbert screws14, staples16, stainless steel wires17, suture anchor18, meniscal arrows19, sutures20-24 or combination 25 of these methods and mini-open or arthroscopic repair26.

The purpose of this study is to evaluate the functional outcomes of the arthroscopic repair of displaced tibial spine avulsion fractures in adults using suture pull out technique using fibertape (Arthrex ,Napels). We hypothesized that arthroscopic fixation using suture pull out technique in adults could give satisfactory functional outcomes along with good knee stability and range of motion.

\section{Materials and Methodology}

A study of 10 patients having displaced tibial spine avulsion fracture (Figure 1, 2) was done at our institute. 


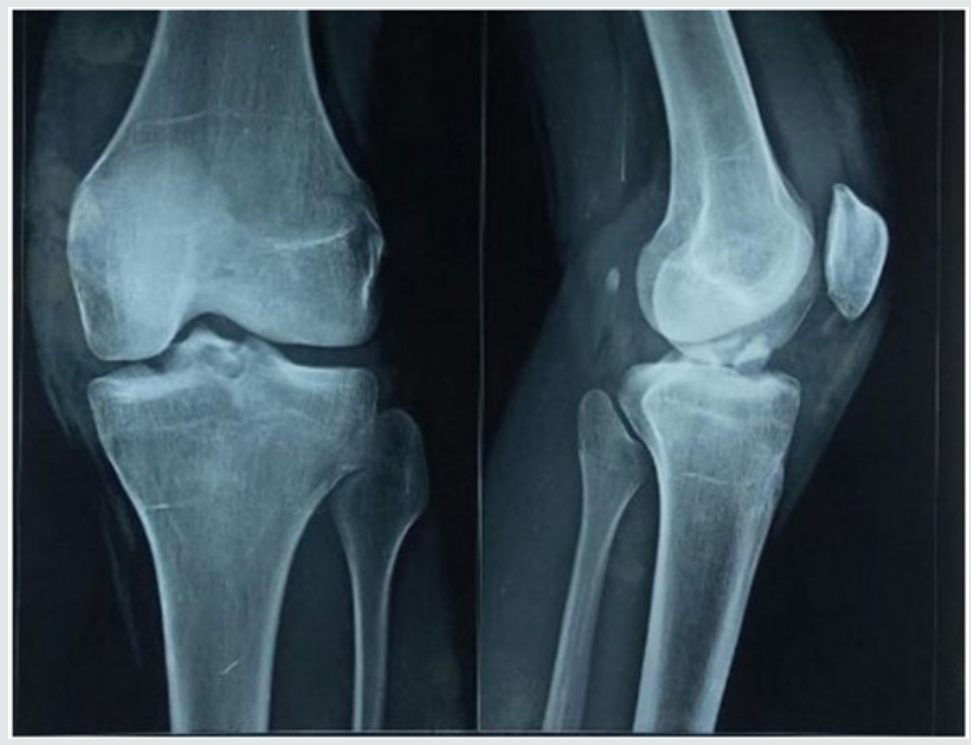

Figure 1: Pre op x-ray.

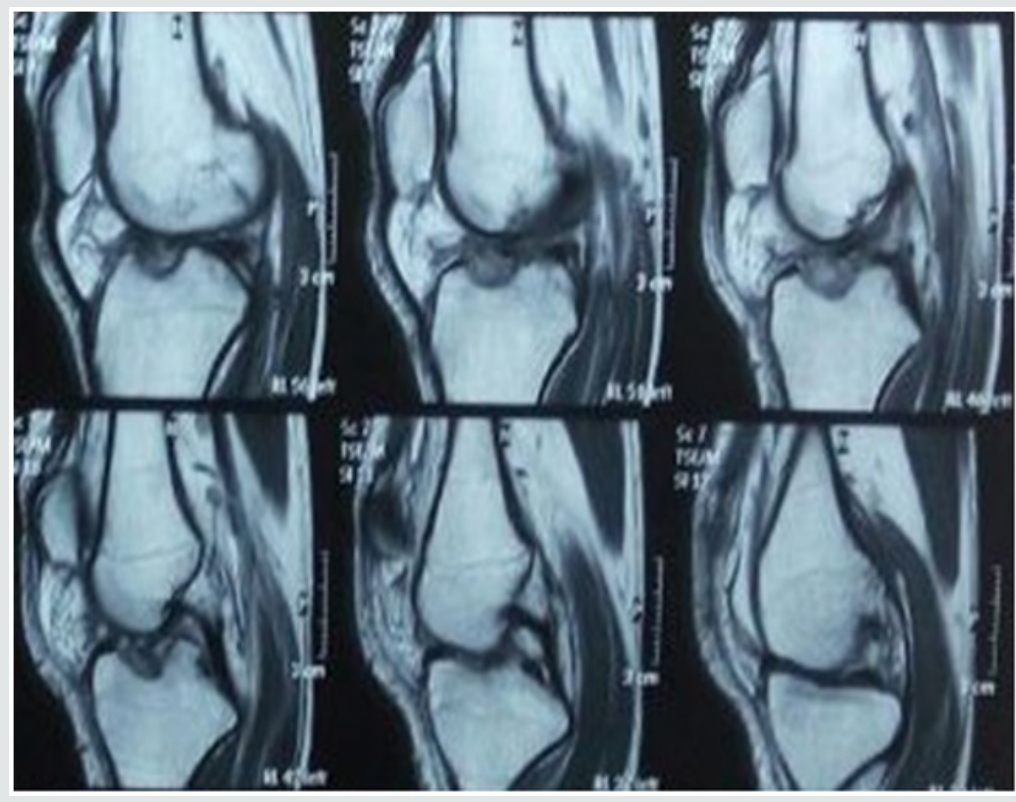

Figure 2: MRI.

- Inclusion criteria were: age $>18$, patients willing to give consent, closed injuries, type 2, 3 or 4 injury (according to Meyer and Makeover classification)

- $\quad$ Exclusion criteria were: patient not willing to give consent, open injuries, multiple ligament injuries

Preoperative work up included clinical examination, AP and Lateral radiographs of Knee, MRI, and blood investigations. Based on the radiological investigations fractures were classified according to Meyer and Mckeever classification. Out of 10 patients 2 patients had type II, 1 patient had type IV and 7 patients had type III injury. All patients were treated by arthroscopic suture pull-out technique using suture tape.
Patient recovery was recorded post operatively which included clinical examination, radiograph after 4 weeks and recording functional outcome using Lysholm Knee score on each follow up.

\section{Operative technique}

All patients were operated by same surgeon after 2 weeks of injury. Under spinal anesthesia patient kept in supine position with affected leg in 90 degree of flexion in leg holder and with tourniquet. Anteromedial and Anterolateral portals made (Figure 3) and diagnostic arthroscopy was done to rule out other associated injuries. Now avulsed fracture fragment identified and soft tissue around the avulsed fragment was debrided with help of shaver and soft tissue interposition along with transverse ligament was removed. 


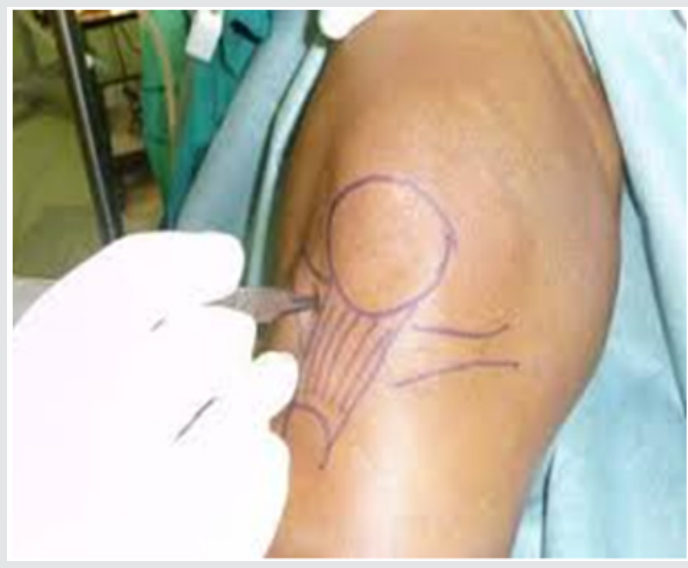

Figure 3: (Standard Arthroscopic Portals).

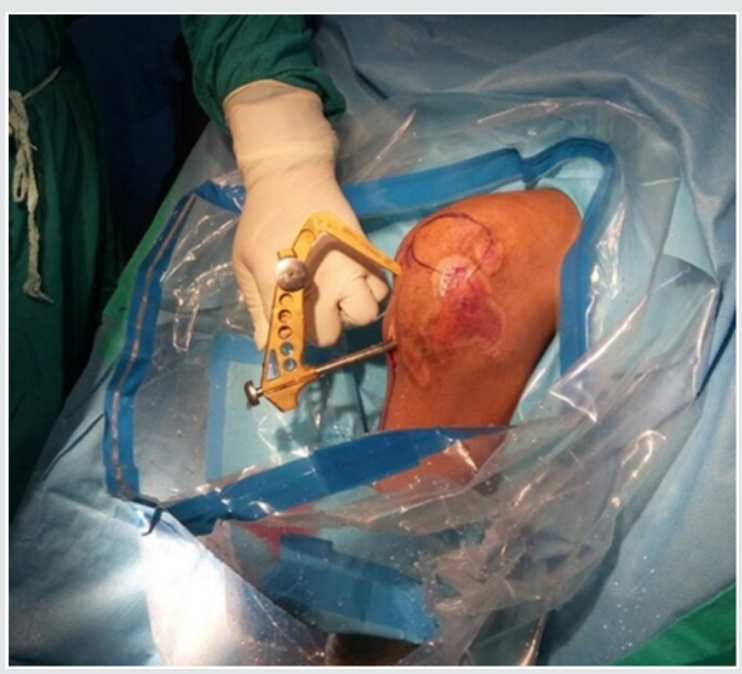

Figure 4: (Making of tibial tunnel with Help of ACL jig).

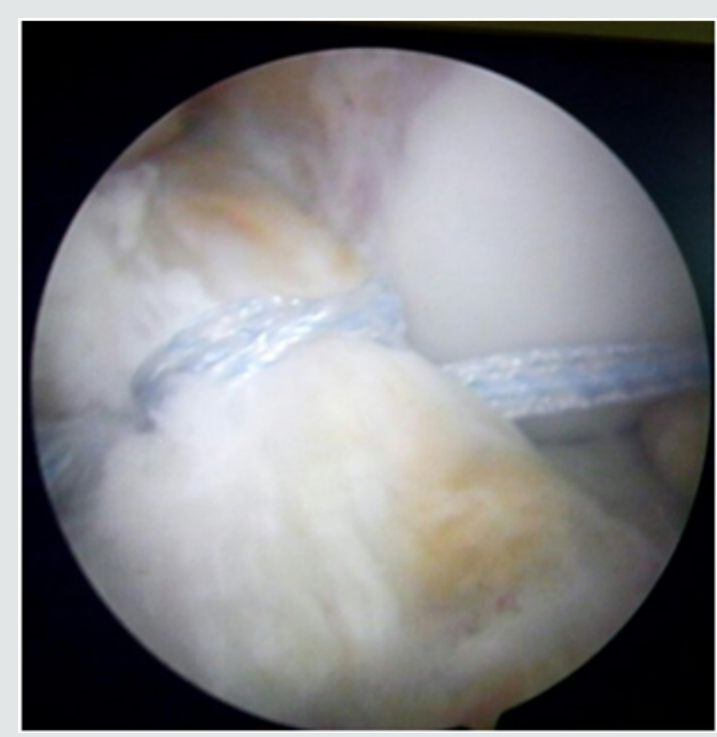

Figure 5: (Strangulation with Fiber tape at the base of attachment of ACL).
Reduction of the fragment is attempted with help of probe and site of the base of fracture fragment in the carter is confirmed. With help of ACL jig 2 parallel tunnels were made (Figure 4) from the anteromedial aspect of upper part of tibia exiting just at the level of tuberosity on either side of base of ACL attachment., Tunnels were made as close as possible to attachment of the ACL without damaging the structure. With help of suture lasso, PDS is passed around the base of ACL fragment and railroading of fiber tape was done. Base of the ACL fragment is strangulated (Figure 5) with fiber tape (Arthrex, Naples) in a crisscross manner with each end of the fiber tape passing through opposite tunnel. Reduction of the fragment was maintained with probe while tying the sutures.

\section{Post Op Rehab}

Patient was immobilized with long knee brace for 2 weeks and partial weight bearing was allowed. After 2 weeks gradual weight bearing walking and knee mobilization started along with passive knee range of motion exercises. After 4 weeks active knee range of motion exercises started with quadriceps stretching and strengthening exercises till next few months. After 6 months postoperatively patients were allowed to return for pre injury activity.

\section{Post Op Evaluation}

All patients were followed up monthly till 6 months and the yearly. On each monthly follow up clinical examination was done which included assessment of knee range of motion and laxity. Monthly AP and Lateral radiographs were taken to see the radiological union. Functional outcome assessment was done by Lysholm knee score on every monthly follow up.

\section{Discussion}

Tibial spine avulsion fractures are rare and occur mostly in age group 8 -14 years [1], though there is increase in the number of this injury in adults has been noted recently [2-4]. This injury is also associated with laxity of the ACL as it is the site of the attachment of the ACL [5]. Fixation of this type of fracture is necessary as they can be the cause of disabilities like loss of range of motion and stability of the knee joint [6-11]. And it is necessary to preserve the native ACL as it has mechanoreceptors for proprioception and neuromuscular control [12]. Various methods have been described to fix this fracture which includes k-wire [13], cancellous screws [14], Herbert screws [15], staples [16], stainless steel wires [17], suture anchor [18], meniscal arrows [19], sutures [20-24] or combination [25] of these methods and mini-open or arthroscopic repair [26]. Suture fixation is relatively better than screw fixation. As there is no need for second surgery for hardware removal, no impingement of the hardware in the notch. Suture fixation is better both, clinically and bio-mechanically [27-29]. the aim for fixation of the tibia spine avulsion fractures is to restore the knee stability and ACL competence. Studies have shown that laxity may 
present even after fixation in $10 \%$ of patients [30]. In our study only 1 patient had post-operative complication in form of inability to full extension (arthrofibrosis), which was improved by regular high intensity physiotherapy. So out of 10 patients 9 patients had satisfactory functional outcomes after arthroscopic fixation by suture pull through technique. All 9 patients reached at the pre injury work level after 6 months of fixation. R Rajanish et al. [31] have done the similar method with the use of wire. But we have used tape as we believe that it causes less tissue compression due to larger surface area with more strength.

\section{Outcomes and results}

The study consisted 10 patients ( 9 male and 1 female). The average age of patients was 23.9 years (Ranging from 18 to 38 years). Mode of injury was sports in 4 patients and Road traffic accident was in 6 patients. Out of 10 patients, 1 patient had type IV, 2 patients had type II and 7 patients had type III injury according to Meyers and Makeover classification. Average time from injury to surgery was 13.6 days. Average radiological union time was 3.8 months. Average follow up time was 12.3 months (Range: 4 to 24) at final follow up functional outcome in form of average Lysholm knee score was 96.7 (Range: 88 to 100). No patient showed signs of ACL laxity at final follow up. All patients reached at pre-injury work level at around 6 months.

\section{Conclusion}

Arthroscopic suture pull-out fixation for tibial spine avulsion fracture results in excellent clinical and radiological outcomes without any significant complications. Use of tape leads to better compression and reduction of fracture fragment due to larger surface area.

\section{References}

1. Hargrove R, Parsons S, Payne R (2004) Anterior tibial spine fracture - an easy fracture to miss. Accid Emerg Nurs 12(3): 173-175.

2. Tolo VT (1998) Fractures and dislocations around the knee.In: Green NE Swiontkowski MF, eds. Skeletal trauma in children. Philadelphia: W.B. Saunders 444-447.

3. Ishibashi Y, Tsuda E, Sasaki T,et al. (2005) Magnetic resonance imaging aids in detecting concomitant injuries in patients with tibial spine fractures. Clin Orthop 434: 207-212.

4. Hayes JM, Masear VR (1984) Avulsion fracture of the tibial eminence associated with severe medial ligamentous injury in an adolescent. A case report and literature review. Am J Sports Med 12(4): 330-333.

5. McLennan JG (1982) The role of arthroscopic surgery in the treatment of fractures of the intercondylar eminence of the tibia. J Bone Joint Surg Br 64(4): 477-480.

6. Meyers MH, McKeever FM (1959) Fracture of the intercondylar eminence of the tibia. J Bone Joint Surg Am 41(2): 209-222.

7. Casalonga A, Bourelle S, Chalencon F, De Oliviera L, Gautheron V, et al. (2010) Tibial intercondylar eminence fractures in children: The longterm perspective. Orthop Traumatol Surg Res 96(5): 525-530.

8. Zaricznyj B (1977) Avulsion fracture of the tibial eminence: Treatment by open reduction and pinning. J Bone Joint Surg Am 59(8): 1111-1114.
9. Sullivan DJ, Dines DM, Hershon SJ, Rose HA (1989) Natural history of a type III fracture of the intercondylar eminence of the tibia in an adult. A case report. Am J Sports Med 17(1):132-133.

10. Panni AS, Milano G, Tartarone M, Fabbriciani C (1998) Arthroscopic treatment of malunited and nonunited avulsion fractures of the anterior tibial spine. Arthroscopy 14(3): 233-240.

11. Koukoulias NE, Germanou E, Lola D, Papavasiliou AV, Papastergiou SG, et al. (2012) Clinical outcome of arthroscopic suture fixation for tibial eminence fractures in adults. Arthroscopy 28(10): 1472-1480.

12. Koukoulias NE, Germanou E, Lola D, Papavasiliou AV, Papastergiou SG et al. (2012) Clinical outcome of arthroscopic suture fixation for tibial eminence fractures in adults. Arthroscopy 28(10): 1472-1480.

13. Furlan D, Pogorelić Z, Biocić M, Jurić I, Mestrović J, (2010) Pediatric tibial eminence fractures: arthroscopic treatment using K-wire. Scand J Surg 99(1): 38-44

14. Doral MN, Atay OA, Leblebicioğlu G, Tetik O (2001) Arthroscopic fixation of the fractures of the intercondylar eminence via transquadrici- pital tendinous portal. Knee Surg Sports Traumatol Arthrosc 9(6): 346-349.

15. Wiegand N, Naumov I, Vámhidy L, Nöt LG (2014) Arthroscopic treatment of tibial spine fracture in children with a cannulated Herbert screw. Knee 21(2): 481-485.

16. Kobayashi S, Terayama K (1994) Arthroscopic reduction and fixation of a completely displaced fracture of the intercondylar eminence of the tibia. Arthroscopy 10(2): 231-235.

17. Oohashi Y (2001) A simple technique for arthroscopic suture fixation of displaced fracture of the intercondylar eminence of the tibia using folded surgical steels. Arthroscopy 17(9): 1007-1011.

18. Vega JR, Irribarra LA, Baar AK, Iñiguez M, Salgado M, et al. (2008) Arthroscopic fixation of displaced tibial eminence fractures: a new growth plate-sparing method. Arthroscopy 24(11): 1239-1243.

19. Wouters DB, de Graaf JS, Hemmer PH, Burgerhof JG, Kramer WL, et al. (2011) The arthroscopic treatment of displaced tibial spine fractures in children and adolescents using Meniscus Arrows®. Knee Surg Sports Traumatol Arthrosc 19(5): 736-739.

20. Huang TW, Hsu KY, Cheng CY, Chen LH, Wang CJ, (2008) et al. Arthroscopic suture fixation of tibial eminence avulsion fractures. Arthroscopy 24(11): 1232-1238.

21. Hunter RE, Willis JA (2004) Arthroscopic fixation of avulsion fractures of the tibial eminence: technique and outcome. Arthroscopy 20(2): 113121.

22. May JH, Levy BA, Guse D, Shah J, Stuart MJ, et al. (2011) ACL tibial spine avulsion: mid-term outcomes and rehabilitation. Orthope- dics 34(2): $p$ 89.

23. Tudisco C, Giovarruscio R, Febo A, Savarese E, Bisicchia S, et al. (2010) Inter- condylar eminence avulsion fracture in children: long-term follow-up of 14 cases at the end of skeletal growth. J Pediatr Orthop B 19(5): 403-408.

24. Wagih AM (2015) Arthroscopic treatment of avulsed tibial spine frac- tures using a transosseous sutures technique. Acta Orthop Belg 81(1):141-146

25. Gans I, Babatunde OM, Ganley TJ (2013) Hybrid fixation of tibial eminence fractures in skeletally immature patients. Arthrosc Tech 2(3): e237-e242.

26. Accousti WK, Willis RB (2003) Tibial eminence fractures. Orthop Clin North Am 34(3): 365-375.

27. Ahn JH, Yoo JC (2005) Clinical outcome of arthroscopic reduction and suture for displaced acute and chronic tibial spine fractures. Knee Surg Sports Traumatol Arthrosc 13(2): 116-121. 
28. Huang TW, Hsu KY, Cheng CY, Chen LH, Wang CJ, et al. (2008) Arthroscopic suture fixation of tibial eminence avulsion fractures. Arthroscopy 24(11): 1232-1238.

29. Shook BJ, Frank HG, Freedman KB (2006) Arthroscopic suture fixation of tibial eminence fractures. Orthopedics 29(7): 577-581.
30. Aderinto J, Walmsley P, Keating JF (2008) Fractures of the tibial spine: Epidemiology and outcome. Knee 15(3): 164-167.

31. Rajanish R, Jaseel M, Murugan C, Kumaran C (2018) Arthroscopic tibial spine fracture fixation: Novel techniques. Journal of Orthopaedics 15(2): 372-374.
(C) Commons Attribution 4.0 License

To Submit Your Article Click Here:

Submit Article

DOI: $10.32474 /$ OSMOAJ.2020.04.000176

$\begin{gathered}\text { Orthopedics and Sports Medicine } \\ \text { Open Access Journal }\end{gathered}$
Assets of Publishing with us
- Global archiving of articles
- Immediate, unrestricted online access
- Rigorous Peer Review Process
- Authors Retain Copyrights
Orthopedics And Sports Medicine:
Open Access Journal

